\title{
Dynamic Characteristics of the End-effector of a Drilling Robot for Aviation
}

\author{
Ying Xu*, Qianfeng Wan, Gang Lu, Benshuang Zhang \\ School of Aircraft Engineering, Nanchang Hangkong University, Nangchang, China \\ Email address: \\ tn416ky@126.com (Ying Xu),1600249323@qq.com (Qianfeng Wan), 1811894355@qq.com (Gang Lu), \\ 631182510@qq.com (Benshuang Zhang) \\ ${ }^{*}$ Corresponding author
}

\section{To cite this article:}

Ying Xu, Qianfeng Wan, Gang Lu, Benshuang Zhang. Dynamic Characteristics of the End-effector of a Drilling Robot for Aviation. International Journal of Materials Science and Applications. Vol. 7, No. 5, 2018, pp. 192-198. doi: 10.11648/j.ijmsa.20180705.14

Received: August 16, 2018; Accepted: November 19, 2018; Published: December 11, 2018

\begin{abstract}
This study discusses the dynamic stiffness of the End-effector of a drilling robot for aircraft. In view of the requirements of automatic drilling processing for aircraft parts, based on the analysis of the working process of the automatic drilling End-effector, the End-effector of drilling unit has been employed in precision machine tools, It can provide very smooth motion and good verticality. In the design of the machines, it is necessary to obtain the stiffness of these guideway. Therefore, an identification method of the guideway stiffness is verified in this paper. In this method, the guideway stiffness is identified from the natural frequency of the moving body. First, a virtual prototype of the End-effector of drilling unit flexible is constructed by jointly using both ANSYS, which provides a foundation for further dynamic characteristic simulations. Next, the impact test is carried out for a drilling tool to obtain the vibration mode of its moving body, and simple vibration model is developed based on the obtained vibration mode to identify the natural frequency of the guideways. For further verification, natural frequencies of the moving body are calculated by FEM with the identified natural frequency and compared with the measured natural frequencies. The results shows that : the natural frequencies were calculated almost correctly with the identified equivalent stiffness, and which provides theoretical reference for improving the drilling efficiency and assembly quality of aircraft components.
\end{abstract}

Keywords: End-effector, Flexible Drilling Robot, Dynamic Stiffness, Modal Analysis, FEM

\section{Introduction}

Robot drilling system is the precise§mechanical equipment in the connection of aircraft assembly, due to the aircraft structure materials of high strength and toughness, high speed, it is easy to have larger impact vibration to the end actuator, which will ultimately affect the hole accuracy and surface quality of parts, and reduce the working life, reliability of the End-effector and the drilling bit [1, 2]. Therefore, the study of the dynamic performance of the End-effector has an important role in improving the drilling precision and assembly quality of the aircraft structure parts. However, the End-effector includes a large number of binding surfaces, and the dynamic characteristics of the End-effector are largely determined by the characteristics of the junction, so the analysis of the dynamic characteristic parameters of the combined part has always been a hot topic in the academic circles at home and abroad [3-5].

$\mathrm{Up}$ to now, there are three main methods to model the dynamic parameters of machining equipment. (1) Testing method: The method is mainly by hammer compaction test to measure the transfer function of the guide rail in the vertical direction and horizontal direction, then based on the modal theory to identify the stiffness and damping coefficient of the two directions and the dynamic parameters of the joint part of the linear guide rail are obtained $[6,7]$. (2) Theoretical calculation method: The method is based on the basic characteristic parameters of the joint, and simplified the combined model to obtain the stiffness and damping of the joint $[8,9]$. (3) The combined method of testing and theoretical calculation: In this method, the dynamic parameters of the guide rail joint are tested by the test method, and then use the finite element method to solve the dynamic design, which provides an effective method for the dynamic design of the machining equipment $[10,11]$. However, it is difficult to accurately describe the parameters of the machine tool joints with the finite element analysis 
(FEA) of machining equipment at present, which can affect the accuracy of the simulation results; the test method can accurately measure the dynamic characteristics of the whole machine, but it needs to have the setting equipment as a test object, and cannot solve the structural optimization of processing equipment in the design stage. So, it is very important to study the dynamic performance of the machining equipment by combining the finite element simulation method and the testing method [3-6].

In this paper, the End-effector of the robot is used as the research object, firstly, the stiffness and damping parameters of the End-effector guide rail are identified by experiments, and the recognition results can be applied to the finite element model of machine tool, and the finite element analysis is carried out on the End-effector; then the modal analysis of the End-effector is performed, and compare the results of the analysis, verify the correctness of the finite element analysis, analyse and identify the weak link of the End-effector, and lay the foundation for the optimal design of structure of drilling system.

\section{Structure of the Drilling End-effector}

The robot system is composed of a joint robot, which is consisted of the End-effector and the pose calibration system, and the End-effector is one of the important parts of the robot system. In this paper, the design of slide type of drilling End-effector constitute the main electric spindle drilling unit slide feed unit, detection unit, compression unit, connecting stent, chip cooling and other auxiliary mechanism etc.

Figure 1 is a slide type End-effector CAD model (omitted pressing unit, detection unit and a dust suction unit). Rolling guide joint has a guide surface between the headstock and the two stage electric slide, as well as the two stage slide and support joint. Each binding surface is composed of a pair of high precision linear rolling guide rails and four guide rails. Due to the strong nonlinear characteristics of the end line attachment, it is not accurate to obtain the parameters of the binding surface [9]. The guide rail interface is one of the most important binding surfaces in the End-effector system, and with the strongest impact to the overall dynamic performance of the End-effector. Therefore, it is important to study the correct identification of the joint parameters of the guide rail, and to establish the overall dynamic model of the End-effector.

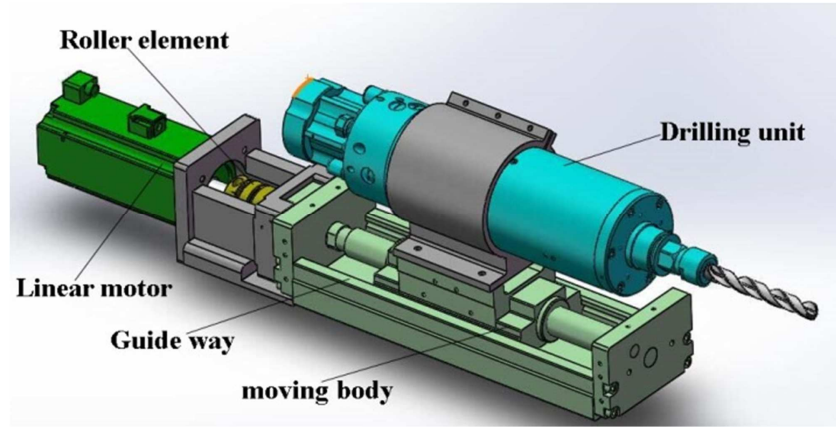

Figure 1. The CAD model of slide type End-effector.

\section{Modal Test Method of Guide Contact Surface}

Experimental modal [12] is an effective method to identify engineering dynamic characteristics by test method, and it is also applicable to the dynamic characteristic analysis of the end effector. In order to obtain the characteristic parameters of the contact surface of the rolling guide rail, on the End-effector of one rolling guide by experimental modal testing.

\subsection{Establishment of the Simple Mechanics Model}

Rolling guide rail vibration is studied by single DOF component analysis method, will guide the normal and tangential are regarded as a single degree of freedom vibration system, guide rail slider contact surface model can be shown in Figure 2: spring damping unit principle diagram to describe. Single point excitation method for multi-point response, the fixing rails using hammer to slide rails were excited along the normal and tangential to test its transfer function in both directions, so that the rail system analysis to identify normal and tangential stiffness and damping.

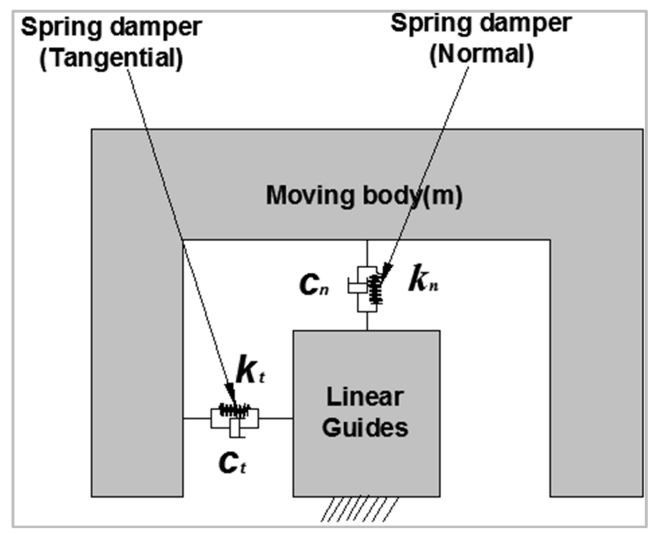

Figure 2. Spring - damping unit schematic.

\subsection{Modal Test Method}

As shown in Table 1, the slider mass and dimensions are listed in Table 1, the slider is driven by a linear motor. The modal test of the contact surface of the guide rail is carried out, and the transfer function is determined by the vibration exciter. The transfer function is expressed with the vibration displacement corresponding to the vibration force, and the vibration displacement is obtained by double integration, and the average value of the measured result is expressed by the 5 times measured results. Figure 3 is the model of the driving system used in this paper. Vibration position in Figure 3 is shown in bold part. Modal analysis is carried out by means of exciting vibration measurement transfer function.

Table 1. Specifications of feed drive.

\begin{tabular}{lll}
\hline \multirow{2}{*}{ Moving body } & Mass & $\mathbf{1 6 k g}$ \\
\cline { 2 - 3 } & Size $(\mathbf{W} \times \mathbf{L} \times \mathbf{H})$ & $\mathbf{2 0 0} \times \mathbf{4 0 0} \times \mathbf{1 0 0}$ \\
\hline Guideways & Rolling elements & Roller \\
Actuator & Type & Linear motor \\
\hline
\end{tabular}




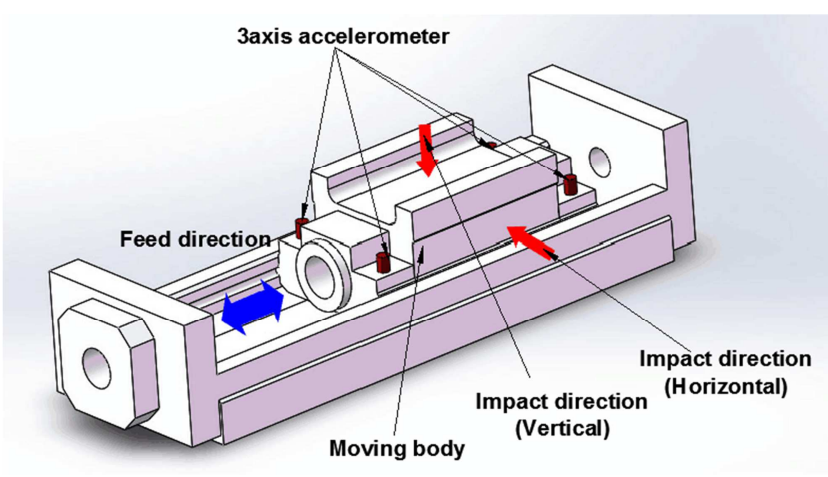

Figure 3. Drive System Schematic.

\section{Testing Results of Guide Rail Vibration Modal}

Figure 4 shows the plumb plane along the moving direction of the guide rail excitation transfer function, figure 5 shows in the horizontal plane along the moving direction of the guide rail excitation transfer function, the two transfer function is 3 axis accelerometer in figure 3 (1) the level of the measured acceleration and plumb direction.

Transfer function of the longitudinal axis of the dynamic response, the size of the dynamic response reflects the degree of interference caused by the vibration of the moving object, has nothing to do with the guide rail surface shape.
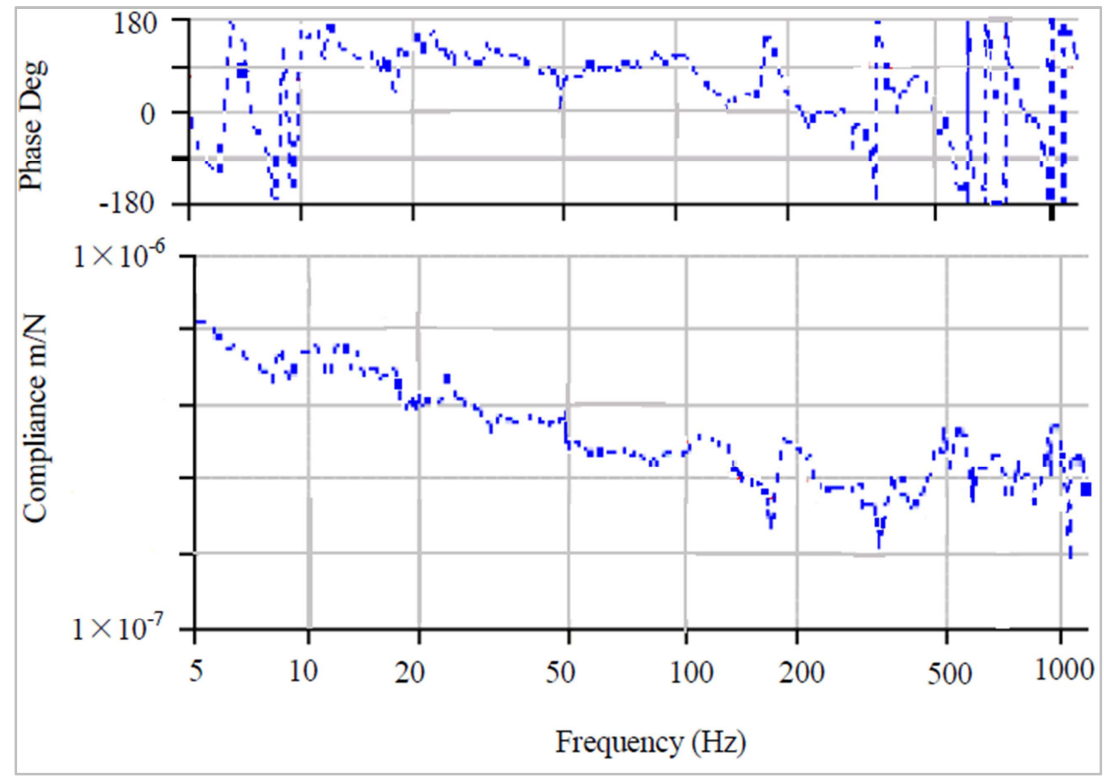

Figure 4. Frequency response of vertical direction.

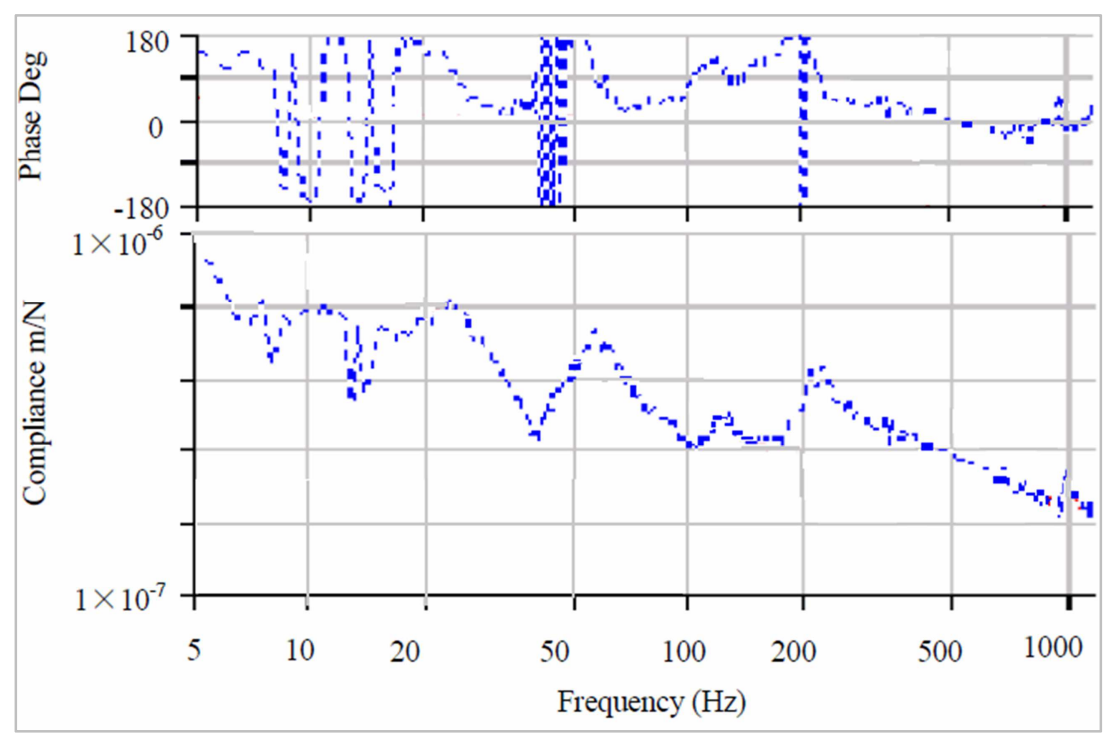

Figure 5. Frequency response of horizontal direction

Figure 4 and figure 5 can be seen, the horizontal direction of the high dynamic response, from the direction of inspection of the guide rail vibration influencing factors, dynamic response high place, illustrating the horizontal direction than perpendicular to the direction of state-owned frequency high prone to vibration. 
From horizontal direction the results of modal analysis, the transfer function of the general rolling guide, the vibration modes of under $200 \mathrm{~Hz}$ has nothing to do with the shape of guide rail, machine all the vibration mode and vibration modal different moving objects. Because it is used for the measurement of ultra precision machinery, so even if the degree of $10 \mathrm{~nm} / \mathrm{N}$ response to the position can be detected according to the measurement of vibration. Namely, the occurrence of the vibration modal is closely related to the stability of the drive system, therefore, guide the vibration characteristic of not only affect the machining precision, also influence its performance. So, to control the vibration amplitude directly affects the system accuracy of hole.

\section{Modal Test Results Verification Based on Finite Element Analysis}

Based on the finite element analysis software ANSYSWorkBench14.0, the finite element model of the
End-effector is established and the grid is divided (shown in Figure 6). On the rolling linear guide rail, the spring damping element combinl4 is used to simulate the characteristics of both elastic and damping of the joint surface, and the guide rail base in the model is fully restrained according to the actual boundary conditions. In order to reduce the end effector's weight, the base guide rail, the slider and the linear guide rail are made of 45 steel, the elastic modulus is 280 GPA, density is $7800 \mathrm{~kg} / \mathrm{m}^{3}$ and the Poisson's ratio is 0.3 . See the static state (assuming zero load) as the object, analysis the vibration modal when a slipway assembly (including the electric spindle drilling unit) move to the middle position of the guide rail (as shown in Figure 7).

Table 2 is the comparison of experimental results and finite element modal analysis results. From table 2, it is known that the deviation between the inherent frequency value calculated by the finite element method and the test value is about $10 \%$. It shows that the method is feasible and can meet the needs of engineering analysis.

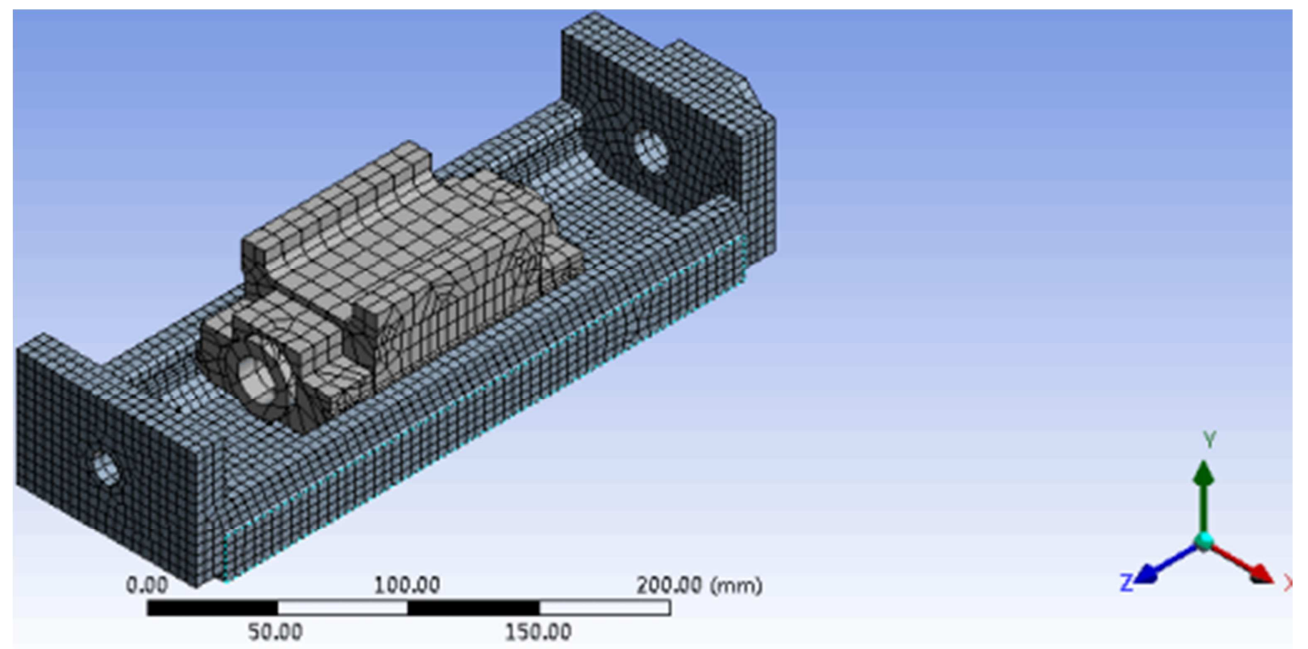

Figure 6. Finite element model of End-effector.

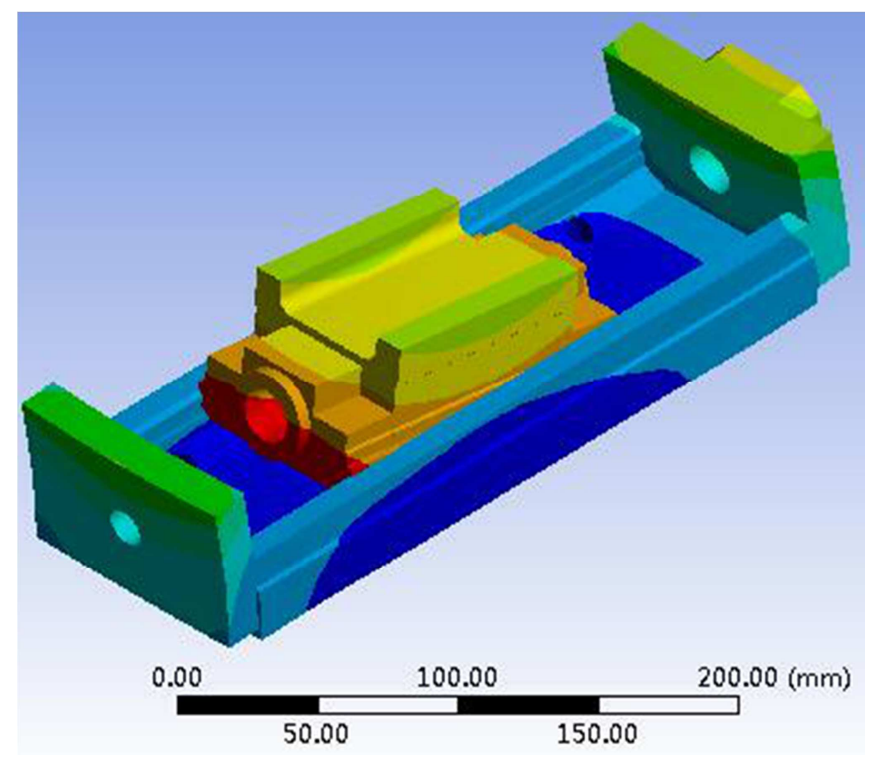

Figure 7. Vibration modes of the End-effector. 
Table 2. Comparison of Natural Frequency.

\begin{tabular}{lll}
\hline Frequency order & Finite element analysis natural frequency $(\mathbf{H z})$ & Test natural frequency $(\mathbf{H z})$ \\
\hline First order & 87.75 & 73.24 \\
Second order & 137.33 & 118.53 \\
Third order & 186.97 & 164.55 \\
Fourth order & 213.56 & 198.32 \\
\hline
\end{tabular}

From the simulated stress nephogram, the stress value of most parts is low, and the local area stress value is higher. The higher stress area appears at the connection between the presser foot bracket and the hole making unit frame guide rail. The position of the reinforced rib strength does not meet the requirements, need to modify the structure.

\section{Structure Optimization of Drilling Unit}

\subsection{Structural Improvement Measures of Drilling Unit}

(1) Analyse the different materials; (2) 8 observation points are established on the front end of the presser foot, the cylinder push rod and the feed axis guide rail, and the deformation data of each observation point is obtained. The layout of observation points is shown in Figure 8. The numbers 1 to 8 are arranged from right to left, and the simulated boundary conditions and loads are the same as above.

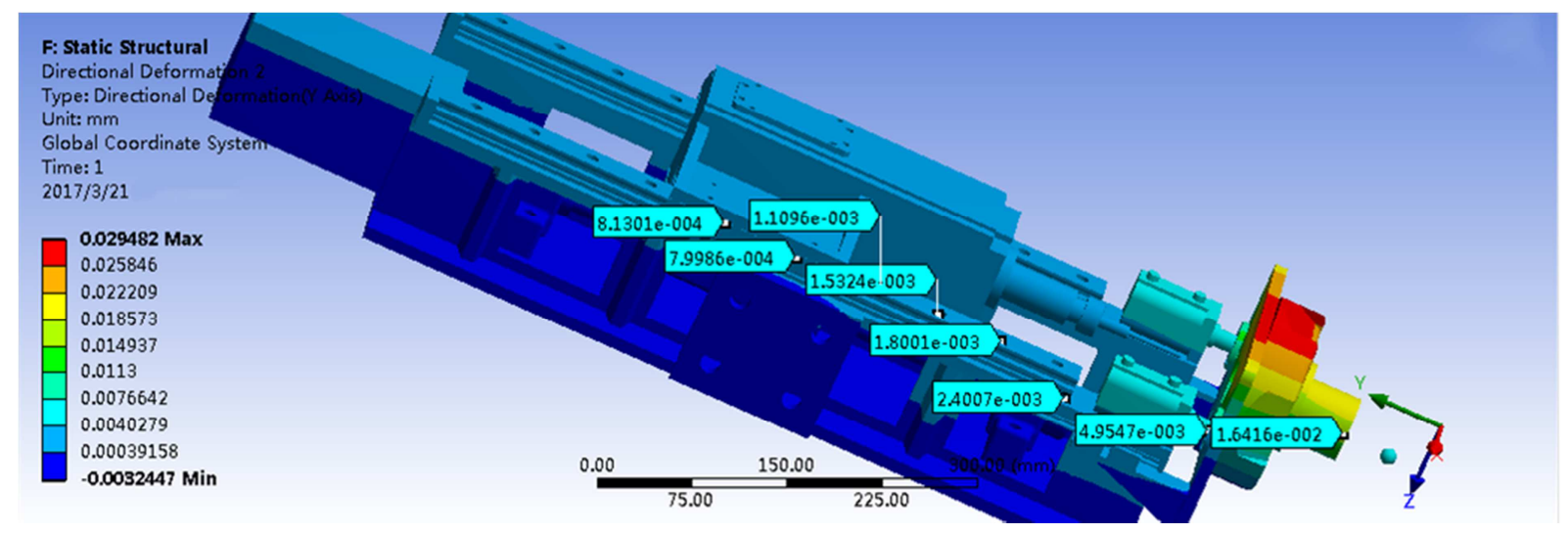

Figure 8. Distribution of observation points.

After the simulation calculation, the post-processing module entering the Workbench brings up the stress distribution nephogram.

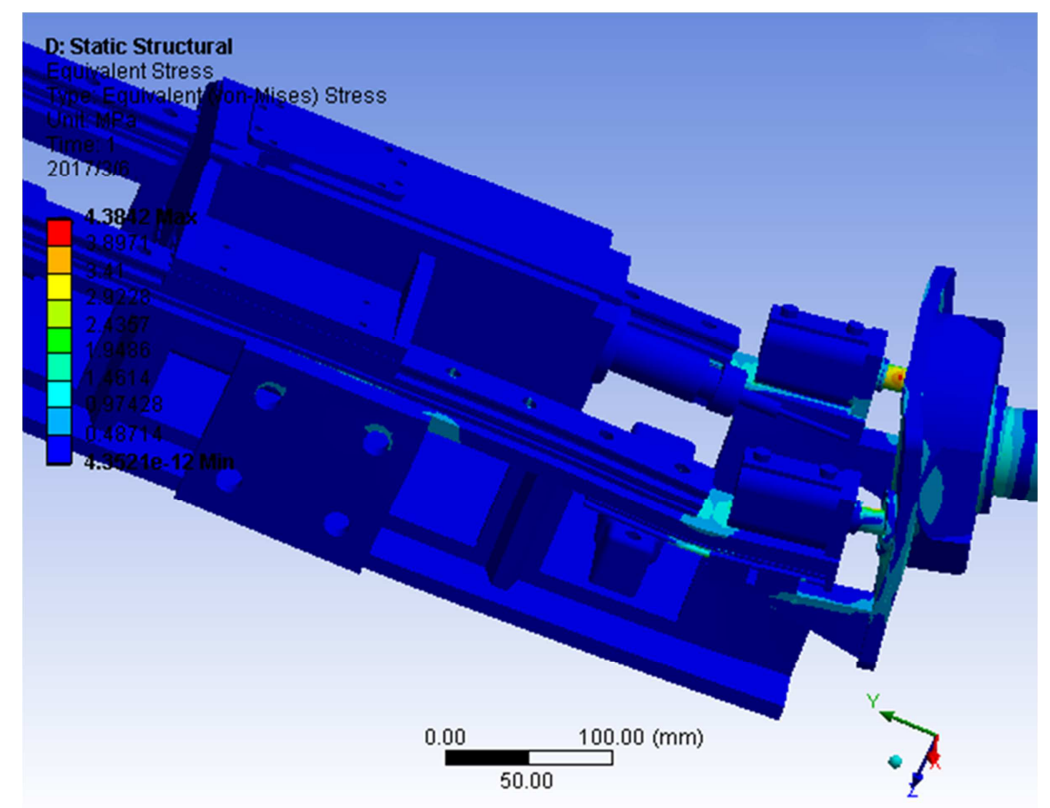

Figure 9. Stress nephogram. 


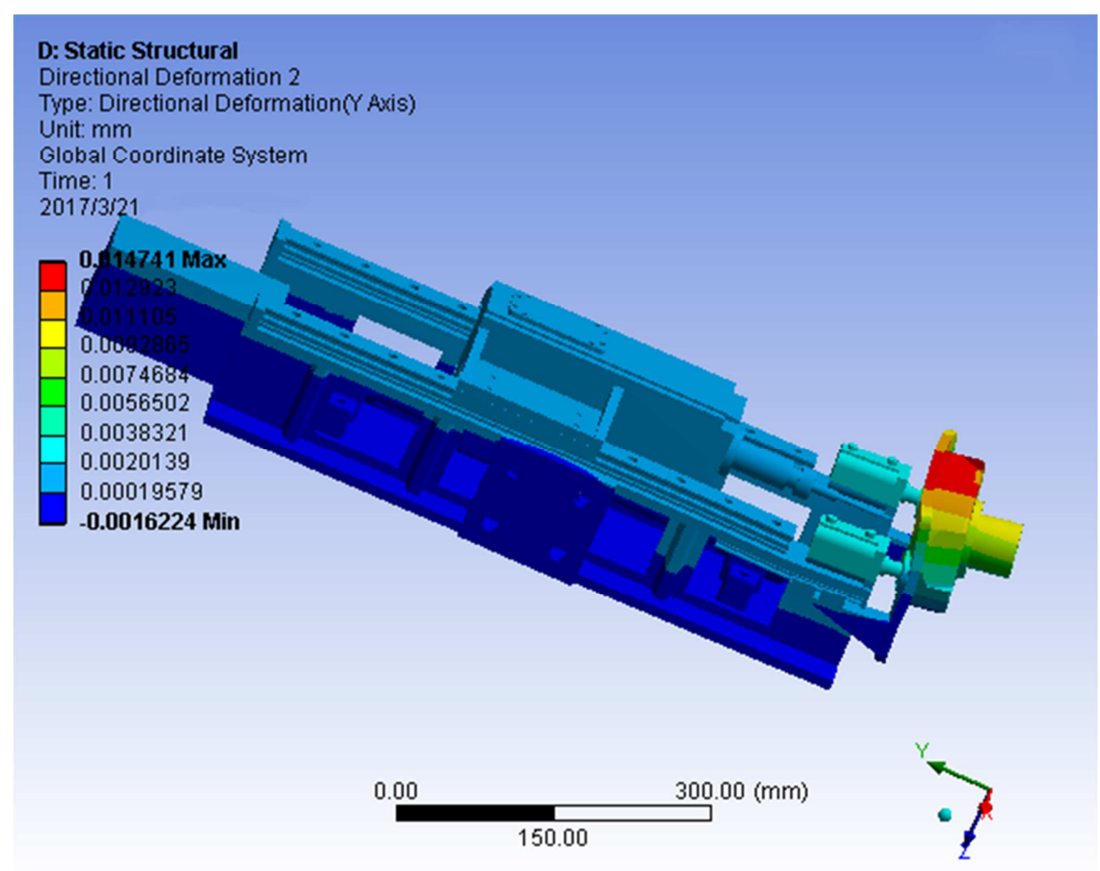

Figure 10. Y-axis direction deformation nephogram.

Figures 9 and 10 are stress nephogram and deformation nephogram after selecting aluminum alloy. As shown in Figure 9, the maximum stress of the hole-making unit appears the cylinder push rod under the action of compressive force, and the maximum stress value is $4.38 \mathrm{Mpa}$.

Figure 10 is a deformation nephogram in the Y-axis direction. The deformation nephogram in the Y-axis direction is the direction deformation nephogram of the pressing force.

\subsection{Analysis of Result}

\subsubsection{Strength Analysis}

It can be seen from the comparison of the analysis results before and after the structure modification in table 3 that the stress value of the structure after modification is significantly reduced, and the static stiffness of the structure is also increased to a considerable extent. The maximum stress value is $4.38 \mathrm{MPa}$ and less than $257 \mathrm{MPa}$, which meets the requirements.

\subsubsection{Static Stiffness Analysis}

It can be seen from table 4 that the static stiffness value is relatively large. The observation point 1 is the position of the pressure foot acting on the compression force, the observation point 2 is the cylinder putter, and the observation point 3 is the front face of the feed guide. From point 4 to point 8 equidistant distribution on feed guide rail.

The above analysis shows that the static stiffness of the action position of the compression force is low and the deformation is large. The static stiffness of the position far from the compression force increases with the distance. The static stiffness of point 1 and point 2 is relatively low, and the static stiffness is obviously improved at point 3 . It shows that the guide rail in the $\mathrm{Y}$ direction has good static stiffness under the action of the pressing force.

Table 3. Comparison table of maximum stress and maximum deformation results before and after modification.

\begin{tabular}{llllll}
\hline & Pressing force & Maximum deformation in Y direction & Maximum stress & Permissible stress & Static stiffness \\
\hline Before modification & $400 \mathrm{~N}$ & $0.018532 \mathrm{~mm}$ & $384.2 \mathrm{MPa}$ & $257 \mathrm{MPa}$ \\
After modification & $400 \mathrm{~N}$ & $0.014741 \mathrm{~mm}$ & $4.38 \mathrm{MPa}$ & $21584 \mathrm{~N} / \mathrm{mm}$ & $257 \mathrm{MPa}$ \\
\hline
\end{tabular}

Table 4. Data from 8 observation points.

\begin{tabular}{|c|c|c|c|c|}
\hline Pressing force & Materials & Number & Deformation displacement & Static stiffness \\
\hline \multirow{10}{*}{$400 \mathrm{~N}$} & \multirow{7}{*}{ Aluminum alloy $2 \mathrm{~A} 12$} & 1 & $0.01039 \mathrm{~mm}$ & $38498.56 \mathrm{~N} / \mathrm{mm}$ \\
\hline & & 2 & $0.00573 \mathrm{~mm}$ & $69808.03 \mathrm{~N} / \mathrm{mm}$ \\
\hline & & 3 & $0.00123 \mathrm{~mm}$ & $325203.3 \mathrm{~N} / \mathrm{mm}$ \\
\hline & & 4 & $0.00081 \mathrm{~mm}$ & $493827.2 \mathrm{~N} / \mathrm{mm}$ \\
\hline & & 5 & $0.00069 \mathrm{~mm}$ & $579710.1 \mathrm{~N} / \mathrm{mm}$ \\
\hline & & 6 & $0.00056 \mathrm{~mm}$ & $714285.7 \mathrm{~N} / \mathrm{mm}$ \\
\hline & & 7 & $0.00043 \mathrm{~mm}$ & $930232.6 \mathrm{~N} / \mathrm{mm}$ \\
\hline & \multirow{3}{*}{ 45\#Steel } & 1 & $0.00597 \mathrm{~mm}$ & $67001.68 \mathrm{~N} / \mathrm{mm}$ \\
\hline & & 2 & $0.00384 \mathrm{~mm}$ & $104166.7 \mathrm{~N} / \mathrm{mm}$ \\
\hline & & 3 & $0.00119 \mathrm{~mm}$ & $336134.5 \mathrm{~N} / \mathrm{mm}$ \\
\hline
\end{tabular}




\begin{tabular}{|c|c|c|c|c|}
\hline Pressing force & Materials & Number & Deformation displacement & Static stiffness \\
\hline & & 4 & $0.00085 \mathrm{~mm}$ & $470588.2 \mathrm{~N} / \mathrm{mm}$ \\
\hline & & 5 & $0.00073 \mathrm{~mm}$ & $547945.2 \mathrm{~N} / \mathrm{mm}$ \\
\hline & & 6 & $0.00059 \mathrm{~mm}$ & $677966.1 \mathrm{~N} / \mathrm{mm}$ \\
\hline & & 7 & $0.00043 \mathrm{~mm}$ & $930232.6 \mathrm{~N} / \mathrm{mm}$ \\
\hline & & 8 & $0.00041 \mathrm{~mm}$ & $975609.8 \mathrm{~N} / \mathrm{mm}$ \\
\hline
\end{tabular}

\section{Conclusion}

(1) According to the experiment, the stiffness and damping parameters of the End-effector guide rail establish the dynamic model of linear guide rail with ball screw pair, define the transfer function of the horizontal and vertical direction of the guide rail joint.

(2) Considering the dynamic effect of the rail joint, analysing the dynamic characteristics of the end effector, make sure that the dynamic parameters of the joint surface is an important factor that affects the dynamic performance of the end effector, especially for the higher order natural frequency.

(3) Compared with the vibration mode results of the End-effector carried out by experimental test and finite element analysis, it shows that the error between the test method and the finite element analysis method is generally less than $10 \%$ in the frequency range.

\section{Acknowledgements}

This paper is one of the periodic achievements of the National Natural Science Foundation of China (Grant No. 51365042) and The Project Sponsored by the Scientific Research Foundation for the Returned Overseas Chinese Scholars, State Education Jiangxi (Grant No. DB201406147). the authors would like to thanks for them.

\section{References}

[1] T. Zeng, C. Liu, Y. Zhu, L Song. "Key Technology Research and Engineering Application for Large Aircraft Digital Assembly,” Aeronautical Manufacturing Technology, 2016.

[2] M. Wang, W. Chen, M. Lin, H. Jiang, L. Yu, and Y. Wang. "Case study of aircraft fuselage automatic assembly simulation," in Proceedings IEEE International Conference on
Mechanic Automation and Control Engineering (MACE), Wuhan, 2010, pp.272-273.

[3] "VERL S. Correlation between feed velocity and preloading in ball screw drives," CIRP Annals-Manufacturing Technology, vol. 59(1), 2010, pp.429—432.

[4] M. YANG, L. GUI, Y. F. HU, G. P. DING, C. S. SONG. "Dynamic analysis and vibration testing of CFRP drive-line system used in heavy-duty machine tool," Results in Physics, vol. 8,2018 , pp.1110-1118.

[5] J. MI, Z. ZHEN, Y. P. ZHU. "Research on Dynamic Characteristics of Machine Tools Based on High Acceleration Processing," Journal of Mechanical Strength, vol. 40(04), 2018, pp.987-991.

[6] Igor Ansoategui, Francisco J. Campa, "Mechatronics of a ball screw drive using an $\mathrm{N}$ degrees of freedom dynamic model," The International Journal of Advanced Manufacturing Technology, Vol.93, 2017, pp.1307-1318.

[7] X. H. WU, Z. R. ZHU. "Research on identification of model parameters for machine tools," Machinery, vol.45(8), 2007, pp.64-66.

[8] D. XU, Q. LIU. "Dynamic co-simulation of NC machine tool based on machine joints modeling," Machinery Design \& Manufacture, vol.3, 2008, pp.9-11.

[9] K. M. MAO, M. X. XING, B. LI. "Dynamic modeling of the movable joint on rolling linear guide," Journal of Huazhong University of Science and Technology, vol.44(07), 2016, pp.81-85.

[10] D. XU, Q. LIU, S. YUAN. "Research on static stiffness of roller guideway,” Machine Tool \& Hydraulics, vol.36(4), 2008, pp.8-10.

[11] D. S. ZHOU, S. L. GUO, Y. L. WANG. "Measurement and analysis of dynamic characteristics of machine tool guideway" Coal Mine Machinery, vol. 38(01), 2017, pp.46-48.

[12] Z. Y. GUO. "Based on Finite Element of Static and Dynamic Performance Analysis of the Whole Machine and Structural Optimization Design," Shenyang University of Technology, 2018. 